\title{
Research on the Physical Conditions of College Students at Present Stage and Targeted Sports Teaching and Education Model
}

\author{
Baichao Xu ${ }^{1}$ \\ 1. Department of Physical Education, Hainan Medical \\ University, \\ Haikou 571100, China; \\ Xiaodong Yang ${ }^{1}$ \\ 1. Department of Physical Education, Hainan Medical \\ University, \\ Haikou 571100, China;
}

\author{
Fusong $\mathrm{Hu}{ }^{2,}{ }_{*}$ \\ 2.Department of Physical Education, Qiong zhou University, \\ Sanya 572022, China
}

\begin{abstract}
In this paper, we conduct research on the physical conditions of college students at present stage and targeted sports teaching and education model. Quality education is to improve the quality of people's physical and mental development and individual for the purpose of education. Sports teaching psychological environment optimization methods are to some extent determines the success or failure of sports teaching, the effective realization of the goal of physical education teaching has very important significance. Our proposed method solves the issues well and in the future, we plan to conduct more literature review to modify the current method to obtain better performance.
\end{abstract}

Keywords: Physical Conditions; College Students; Targeted Education Model; Present Stage.

\section{Introduction}

At present, the college sports class, most teachers are still in the traditional teaching mode, it is largely confined the development of college students' innovative thinking ability, in fact, the university classroom should have the feature of openness, university teaching stage of the teaching purpose is to cultivate students' innovation ability and the ability to adapt to society, if still adopts the traditional teaching mode, it is hard to promote the all-round development of students and the introduction of the inquiry-based learning mode can be very good to solve this problem, of course, in some colleges and universities, the teachers also realized the advantage of inquiry-based learning mode, also began to actively apply them in sports teaching in university. Quality education is to improve the quality of people's physical and mental development and individual for the purpose of education. Quality education depends on sports, sports teaching is basic organization form of school sports. It is the student to obtain knowledge, skills, enhanced physique and intelligence development which will accept the important way of ideological and the moral education models and realize the goal of school physical education and the implementation of quality education is the center. In the sports teaching in the past, our heavy sport is the basic knowledge of learning. Light sports discipline ability: heavy motor skill to master. Quality-oriented education wants to cultivate talents with innovation spirit and practice ability, advocating characteristic education and personality education and therefore, we must change education idea, correct education ideas [1-2].

Creation of enjoyable sports classroom teaching environment in a certain sense and to achieve the goal of physical education teaching and the improvement of sports teaching effect and the implementation of the sports are closely linked. Sports teaching psychological environment optimization methods are to some extent determines the success or failure of sports 
teaching, the effective realization of the goal of physical education teaching has very important significance. Club one prominent feature of the system of physical education teaching is the teaching activities are to students as a starting point, the maximum meet the needs of students in physical exercise. Secondly, in teaching guiding ideology, pay attention to the cultivation of the students' interest in physical exercise, pay attention to in the sports activities of middle school students' subjective initiative. Finally, in the form of teaching, students can choose their interested in specialized course, and the curriculum content, class time and test programs can give full consideration to be fond of students.

Interpersonal relationship in the sports teaching in fact he is in the sports teaching psychological environment is a very important factor, in the modern age, the educationalist believes, meaningful learning is based on the real right relationships, attitudes, and literacy. Interpersonal relationship in the sports teaching in fact he is between teachers and students, students and students of interpersonal relationship, it is the most sensitive psychological environment, one of the most influential factors, it directly affects the teaching and learning between teachers and students of cognitive, emotional and behavioral reflection [3]. The figure one reflects our idea in detail.

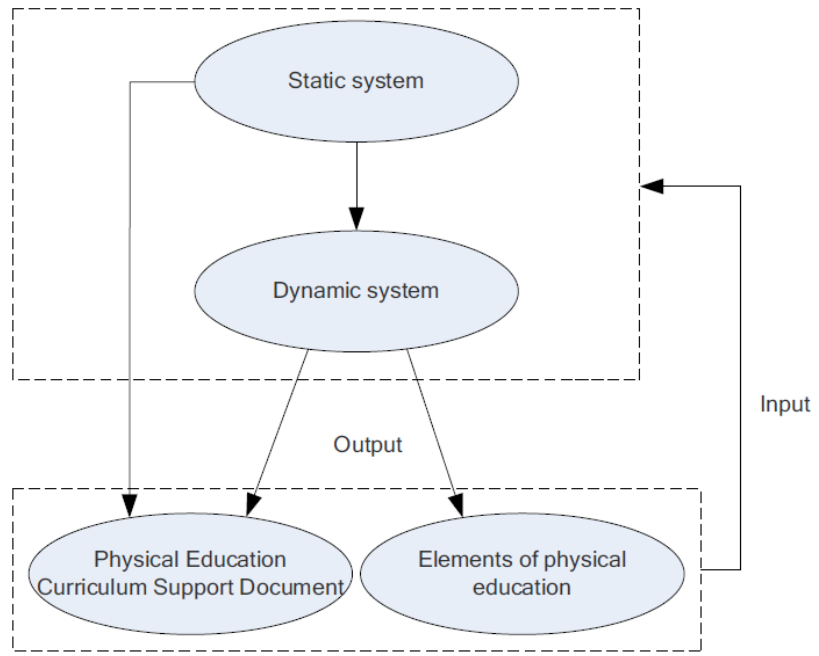

Figure 1. The Concept of the Targeted Sports Teaching and Education Model
In this paper, we conduct research on the physical conditions of college students at present stage and targeted sports teaching and education model. This article through to the understanding of the physical education teaching psychological environment and interpersonal relations in university sports teaching psychological environment present situation analysis, from different point of view put forward some optimize the psychological environment in physical education teaching method and the suggestion, the utilization of sports teaching in physical education teaching for us various favorable factors of psychological environment, suppress and eliminate the various unfavorable factors, the creation of the best sports teaching psychological environment is of important theoretical and practical significance. More detailed discussion will be conducted in the following parts.

\section{The Proposed Methodology}

The Basic Pattern of Physical Education. The purpose of college physical education teaching task is to promote the all-round development of body and mind, effectively enhanced physique, promote the student to develop morally, intellectually and physically, make its have ideal, morality, culture and discipline of professional construction personnel. Therefore, we should make the students master several principles and methods of the exercise of lifelong benefit. Raise the level of sports technology. Strengthen ideological education, to serve the socialist construction. According to the characteristics of the college students' personality development, causes the student in the teaching main body, initiative and creativity. Quality education not only demands students fitness, mastering the basic fitness method, strengthen students' sports consciousness, improve the students' sports ability, to lay a good foundation for lifetime sports, and to students to master some basic knowledge of sports, technology, skill and movement method. Get into the habit of exercise which will 
improve the body quality, in order to better engage in lifetime sports, more to cultivate students' moral and will quality. These new ideas, teaching are basic guarantee to improve the quality of sports teaching to guide us.

For a long time, the sports curriculum reform around how to improve the students' interest, to make the contents of physical education curriculum adapt to the needs of students, improve the enthusiasm of students. Although has obtained the certain result, but the effect is not obvious, the universities sports teaching and no qualitative change, the students' interest in participation did not improve, and even some universities have decreasing trend. In addition, with increasing employment, survival pressure, the contradiction between social demand and school personnel training, the students' social requirements has become increasingly obvious, and the existing sports curriculum content can't fully meet their social needs. Expand training through careful planning, careful preparation, the choice of targeted content, to satisfy the needs of the different stages of students gradually improve their physical quality, psychological quality which will improve their ability of social adaptation. Optimize the environment of physical education teaching, to improve the teaching quality, improve the efficiency of sports teaching has an important significance. Therefore, sports teaching psychological environment will directly influence the progress of the physical education teaching and its effect. If the repressed psychological environment, students' personality development will be constrained, students learning objective is not clear, lack of learning interest, also is impossible to mobilize their learning initiative and enthusiasm, to reach the purpose of the school sports teaching of physical education and requirements. How to create the certain pattern in sports teaching can make teachers and students to strive forward and give full play to the potential of the psychological environment that is what we are one of the important tasks of physical education teaching reform.

The Targeted Sports Teaching and Education Model. National physical fitness and health level is chardonnay should reflect the comprehensive national strength. Also is an important symbol of social civilization and progress. Youth is a country and the hope of the future. Its relationship to the entire national health quality and the youth physical and mental health, strong-willed is full of vitality. It is the embodiment of a thriving vitality of a nation. It is the sign of social civilization progress which is the foundation of the national competitive. In the medical history of physical vulnerable groups of students in common colleges and universities, dietary and nutrition, routine and on the basis of investigation to understand, trying to improve physical vulnerable groups of students in common colleges and universities sports teaching intervention physical and psychological conditions, thus make the physical and mental health of physical vulnerable groups in colleges and universities students is beneficial to improve, and promote the university sports teaching truly peopleoriented concept, make university sports education a breakthrough in the true sense.

Mental ability and physical ability is selfevident in the position in the sports teaching activity, good psychological ability and good physical ability for physical education teaching activities to say so. Therefore, to explore the students' mental ability and physical ability is very necessary. Physical ability is very important to the success of the task. The success of the sports activities such as some required stamina, finger flexibility, leg strength as well as other related ability, so need analysis in sports teaching activity, determine the level of physical ability of students, in order to better play to the potential of students, the sports activities is more free and comfortable. Constitution refers to the quality of the human body. It is hereditary and acquired based on the morphological structure of the human body. 
Physiology and psychological factors, relatively stable characteristics of comprehensive. Genetic is congenital condition of development and changes of people's physique. Relationship is important to one's physical strength, such as size, appearance, character, function, and many other aspects related to genetic diseases and life. But the genetic influence on constitution provides only possibility, but eventually they still depend on the day after tomorrow on the strength of the physical environment. Through physical exercise and health care work the day after tomorrow, it could be improved and improve. It is the most active and the most effective way to enhance physical fitness. Comprehensive evaluation of physical strength has the following five aspects [4]. (1) Body shape development level. (2) Physical quality and athletic ability level. (3) Psychological development status. (4) Physiological and biochemical function level. That is, the body's metabolism and each system and organ work efficiency. (5) Ability to adapt.

As we all know, the sports teaching activity which cannot leave the power factor. Whether running, long jump, or football, basketball, power factors undoubtedly plays an important role. Running, long jump need students have good power, basketball, football is the dynamic force, body strength, static strength and explosive force of the integrated use of evidence, basketball and football are for a long time, also is the use of dynamic process; Trunk power use, especially abdominal strength using the most typical is the basketball shooting, football gets up at the moment of this time in great need of trunk power booster; Static strength static defense in basketball is the embodiment of the very best; The explosive force is frequent in many sports. The role of power in the sports teaching activities embodied in many aspects, if there is no accurate balance and use of power, perfect is impossible to have sports. The body's ability to adapt to the environment is essentially people were affected by the external environment influence. Constantly adjust the body, make it in a state of normal stability function activities. The change of natural environment is objective existence. To achieve the balance of human body with the outside world, must depend on constantly adjust to increase ability to adapt.

The Combination of the Model and Present Stage. At present, our country's colleges and universities sports teaching is still restricted because of some concepts, overall, too much overall general requirements, education for students of sports obsessed with grades and as a result, too many competitive standard requirement for technology, excessive emphasize on strengthen body physiological efficacy, but ignore the healthy heart function, to explore in this field is still in the early stages of understanding. For a long time in our country in the sports teaching goal is for students to strengthen physical health is given priority to, the training focus on sports skill level is too high. In fact, the world health organization has the general and accurate definition of the concept of health has a very comprehensive, health is not just a disease, it should be including physiological, psychological state and adaptability, etc. which will be meaningful and necessary.

In sports teaching system should be focus on these factors, as the students' physical quality and test standard evaluation standard, only the pursuit of blindly movement technical achievement, too utilitarian, without fully considering the education purpose, ignore students' mental health education and social adaptation ability, then to the formation of students' personality, ability to ascend without any real help, also to the students to give full play to the character of the show and blocking effect. Because of the limitation of various objective factors in the college students psychological and physical education of our country on the way there have been some problems, at the same time, because of the lack of external power, the implementation of the mental health education is difficult to get real, for students in sports teaching and psychological 
aspects of care must find a more effective way. In addition, in the teaching of sports, but also from the original physical education into cultural education in general, not simply for a simple physical education, sports skills and knowledge but to teach students the system of students, so as to achieve the purpose of comprehensive development.

\section{Conclusion}

In this paper, we conduct research on the physical conditions of college students at present stage and targeted sports teaching and education model. In university education, physical education teaching is to improve the students', intellectual, physical, the development play a considerable role. The college students in the future life road, also has a big role in the development of the sports teaching can not only activities in the muscle, also can promote students' learning motivation. Promote the development of sports enterprise in our country. In university sports teaching, mainly is the study of sports knowledge and skills. Not only will make the students master the basic knowledge of sports skill. It can make students more cheerful and lively which also help to students' physical and mental health. Our proposed method will help enhance the performance of the classes.

\section{Acknowledgement}

[Funds] Hainan Province Natural Science Fund Project (Grant No.: 314090) ; Hainan province colleges and universities scientific research project (Grant No.: Hnky2015-34); Hainan Medical Humanities Research Base of scientific research project (grant number: QRYPT2015012); Hainan Medical University research and Cultivation Fund (approval number: HY2013-07).

\section{References}

[1] Liu F J, Yang S Y. Investigation and analysis of present conditions of physical education for college students in "Eastern University City"[J]. Journal of Southwest University for Nationalities.

[2] Timothy A. Brown, Thomas F. Cash, \& Steven W. Noles. (1986). Perceptions of physical attractiveness among college students: selected determinants and methodological matters. Journal of Social Psychology, 126(3), 305-316.

[3] Rong-Zhi L I. Research on the Present Conditions of Development of Mass Organization of P.E.in College and Universities-A Case Study of Zhejiang Province[J].

[4] Zhang H C, Sheng J H. An Educational Thought on Improving College Students' Consciousness of Physical Exercise for Fitness[J]. Academic Exploration, 2013. 